\title{
Effect of inclusion of crumb rubber on the unconfined compressive strength and wet-dry durability of cement stabilized clayey soil
}

\author{
Yadav J S*, Tiwari S K \\ Department of Civil Engineering, Malaviya National Institute of Technology Jaipur, India \\ * Corresponding Author: jitendershine@gmail.com
}

Received : 21-11-2016

Revised: 19-12-2016

Accepted: 26-12-2016

\begin{abstract}
In the present study, the effect of inclusion of waste crumb rubber and cement on the unconfined compressive strength and wet-dry durability of clayey soil has been investigated. Crumb rubber and cement were added to clayey soil at ranges of $2.5 \%-10 \%$ and $3 \%-6 \%$ respectively. The results of the investigation revealed that the incorporation of crumb rubber influenced the unconfined compressive strength, axial strain at failure, energy absorption capacity and wet-dry durability of the cement-stabilized clay. The study reveals that as the content of crumb rubber in the cement-stabilized clayey soil increases the unconfined compressive strength decreases but prosperously changes the behavior of the cement-stabilized clay from brittle to ductile. The axial strain corresponding to peak axial stress and energy absorption capacity of the specimens can be increased by limiting the content of crumb rubber up to $5 \%$. The weight loss of the cement-stabilized clay mixed with crumb rubber increases as the content of crumb rubber increases. With the prolongation of the curing period, the weight loss of cement-stabilized clay mixed with crumb rubber decreases. Further, the weight loss of 90 days cured specimens of clayey soil incorporated with $6 \%$ cement and crumb rubber up to $5 \%$ meets the recommendation of the material to be used in construction of road pavements as a base, sub-base, and shoulder. Most importantly, the utilization/disposal of this hazardous waste material reduces its impact on environment and health.
\end{abstract}

Key words: Crumb Rubber, Cemented Clay, Compaction, Unconfined Compressive Strength, Energy Absorption Capacity, Durability, XRD, SEM.

\section{Introduction}

The Industrialization and urbanization have been the two worldwide phenomena in the present century. Though these are the necessity of the society, nevertheless their negative impacts on the environment and social life cannot be demitted. The major ill effect of these global processes is the production of large quantities of industrial wastes (such as incineration ash, plastic waste, rice husk-ash, fly ash, waste rubber tires etc.) and the problems related to their safe disposal and management. The safe and profitable disposal of these wastes is one of the greatest challenges before of industries.

Disposal of discarded waste tires is one of the primus problem faced by the industries and Government of many country because it has a momentous share in the solid waste. About 1.5 billion tires are produced in a year, throughout the world and per annum almost 1000 million tires reach the end of their useful life. In India, a phenomenal increase in the number of automobiles has been noticed. In year 2010-11, the total production of tires was 124.3 million and became 146.1 million in the year 2014-15 (ATMA, 2015)

The common practice used for the disposal of the waste tire such as stockpiles, landfills and burning are considered as a big danger to the health of humans and ecological systems. The stockpiling provides breeding sites for mosquitoes and rodent, whereas heaving of the ground has been faced with landfills disposal of waste tires. The poisonous gasses liberated by the burning of the waste tire, when used as a fuel in the industry causes serious health hazards to the population living nearby that area. Although, many countries have banned the use of tires as a fuel for the industries. Indian Government restricted the import of used /retreaded Tires since 
April 2006. Still, the disposal of discarded waste tires is one of the major problems faced by the nations. Therefore, timely action regarding the safe disposal of waste tires is necessary, keeping in view the environmental problems and health hazards associated with it. One of the common and feasible ways to utilize these waste products is to explore their use in the construction of roads, highways, embankments and a fill material.

Due to rise in population and an increase in infrastructure growth in metropolitan areas, there is a dramatic increase in the prices of land and lack of suitable sites for development. Therefore, now-a-days construction is also being carried out on marginal sites having extremely poor ground conditions like soft clays that were earlier considered unsuitable due to their poor strength and high compressibility. Such soils, when loaded, cause excessive settlements and early failure of structures. It is a challenge to the geotechnical engineer to improve the mechanical properties of the clayey soil by using stabilization and reinforcement techniques at a reasonable cost.

The problems associated with the disposal of waste tires and stabilization of problematic soft/weak soils has encouraged the authors to do this investigation. The use of discarded waste tires as an engineering material is gaining popularity among civil engineering fraternity due to its low density, high strength, hydrophobic nature, low thermal, conductivity, durability, resilience and high frictional strength, which are essential from the geotechnical engineering perspective. ASTM D6270-98 lays guidelines pertaining to use of waste tires in civil engineering.

\section{Background}

The incorporation of waste rubber tire affects the properties of the clayey soils. Various investigators (Al-Tabbaa et al., 1997; Cokca and Yilmaz, 2004; Akbulut et al., 2007; Robani and Chan, 2008; Ho and Chan, 2010; Cabalar et al., 2014; Srivastava et al., 2014; Wang and Song, 2015; Beena et al., 2016) had studied the effect of inclusion of waste rubber tire on the unconfined compressive strength of the cohesive soils. Al-Tabbaa et al. (1997)observed a decrease in unconfined compressive strength of kaolin, bentonite and kaolin-lime with the inclusion of shredded tyre of sizes 1-4 mm, 4-8 $\mathrm{mm}$ and 8-12 mm ranging between $2 \%$ to $20 \%$ by weight. A loss of 19.3\%, 15.6\%, and 9\% (approx.) in UCS of kaolin, kaolin-lime, and bentonite containing $2 \%$ tyre of size $1-4 \mathrm{~mm}$ was reported as compared to untreated soil samples. Whereas, inclusion of $10 \%$ tyre of size $1-4 \mathrm{~mm}$ led to a loss of $43.1 \%, 40.7 \%$, and $30.6 \%$ (approx.) in the UCS of kaolin, kaolin-lime, and bentonite clay. Cokca and Yilmaz (2004) reported about 35 times reduction in the unconfined compressive strength of fly ash-rubber-bentonite mixtures as rubber increases from $0 \%$ to $10 \%$ and bentonite decreases from $10 \%$ to $0 \%$. The inclusion of tire fibres of length $10 \mathrm{~mm}$ up to $2 \%$ increases the unconfined compressive strength of the clay was reported by Akbulut et al. (2007). Robani and Chan (2008) had treated the soft soil with $5 \%$ cement content and tire chips (passing $2 \mathrm{~mm}$ sieve) varying from $5 \%$ to $15 \%$. The unconfined compressive strength the soil incorporated with cement (5\%) and tire chips (5\%) was found to be more than the cement treated soil. The elastic properties of the cement treated soft soil could be increased with the inclusion of tire chips. Ho and Chan (2010) concluded that the inclusion of rubber chips in the cemented kaolin specimens reduces the unconfined compressive strength but were able to increase axial strain corresponding to peak axial stress. A loss of $6.7 \%, 15.25 \%$, and $23.7 \%$ (approx.) was noticed in UCS of kaolin clay stabilized with 2\% cement and incorporated with 5\%,10\% and 15\% rubber chips as compared to cement stabilized kaolin clay. Similarly, a lowering of $19.6 \%, 38.2 \%$, and $43.17 \%$ (approx.) in UCS of cemented kaolin clay containing $4 \%$ cement and $5 \%, 10 \%$ and $15 \%$ rubber chips was reported. Guleria and Dutta (2012) observed the decrease in the unconfined compressive strength of the fly ash-limegypsum mixture with increase in dry/wet tire chip content (5\% to $15 \%$ ) citing two possible reasons: (i) non polar nature of rubber, which entrap air during the mixing and (ii) negligible load taking ability of rubber as compared to the hardened mix. Kim and Kang (2013) had noticed a gradual increment in the unconfined compressive stress of clayey soil with increased strain after reaching a yielding stress with the increase in rubber content. The elastic compression of the crumb rubber was attributed as a reason for such behavior. Cabalar et al. (2014) carried out 
an investigation on the unconfined compressive strength of clay stabilized with lime $(0 \%, 2 \%$, $4 \%$ and $6 \%$ by dry weight) and tyre buffing ( $0 \%, 5 \%, 10 \%$ and $15 \%$ by dry weight). The addition of lime was found to increase the unconfined compressive strength but the inclusion of tyre buffing reduces the strength of the specimens. The inclusion of $5 \%, 10 \%$, and $15 \%$ tire buffing led to a loss of $63.8 \%, 72.2 \%$, and $77.8 \%$ in UCS of clay containing $6 \%$ lime as compared to unrubberized clay stabilized with 6\% lime. Hambirao and Rakaraddi (2014) had noticed an increase in the unconfined compressive strength of the cement stabilized clayey soil with the addition of shredded rubber tyre chips up to 5\%, thereafter it decreases. Prasad et al. (2014) had found an improvement in the unconfined compressive strength of two different soil samples by addition of crumb rubber ( $425 \mu \mathrm{m}$ to $600-\mu \mathrm{m}$ size) up to $10 \%$ and $15 \%$, further addition leads to decrease in the strength. An approximately $60 \%$ improvement the undrained cohesion value of black cotton soil with the inclusion of coarse size ( $4.75 \mathrm{~mm}$ passing $-2 \mathrm{~mm}$ retaining) shredded tyres waste as compared to pure soil was reported by Srivastava et al. (2014). Otoko and Pedro (2014) observed that the addition of shredded tyres of length $10 \mathrm{~mm}$ to $20 \mathrm{~mm}$ up to $5 \%$ leads to increase the UCS values of cemented soil. Wang and Song (2015) had incorporated different fineness of crumb rubber $(30 / 40,60 / 80$ mesh) in clayey soil stabilized with $7 \%$ and $20 \%$ cement content and observed that inclusion of crumb rubber resulted in a decrease in the compressive strength. The inclusion of $5 \%, 10 \%, 15 \%$, and $20 \%$ crumb rubber of size $30 / 40$ mesh in clay stabilized with $20 \%$ cement and cured for 91 days led to a reduction of $7.3 \%, 18.5 \%, 18.5 \%$, and $31.4 \%$ respectively in the compressive strength of cement stabilized clayey soil. Similarly, a reduction of $14.2 \%, 14.2 \%, 24.2 \%$, and $31.4 \%$ was reported in the compressive strength of same mixtures with the inclusion of crumb rubber of size 60/80 mesh. The bad connection between non-polar rubber particles and polar cemented clay particles leads to the creation of voids in the matrix and reduces the strength consequently. The unconfined compressive strength of the rubberized cemented clay was found to be almost independent of the size of rubber particles. Beena et al. (2016) investigated the effect of different size and content of crumb rubber on the unconfined compressive strength of clayey and silty soils. They found maximum unconfined compressive strength with the inclusion of crumb rubber between $2 \%$ to $4 \%$ regardless of the size of crumb rubber. The unconfined compressive strength of clayey soil decreases with the increase in the size of crumb rubber used, whereas it increases with the increase in the size of crumb rubber in case of silty soils.

Only one study is available in the existing literature on the effect of inclusion of waste rubber tires on the durability characteristic of soils. Guleria and Dutta (2013) reported that with the increase in the content of tire chips in fly ash-lime -gypsum mixtures the weight loss increases. The dissimilar thermal expansion of tire chips and fly ash-lime-gypsum mixtures during the drying cycle caused a reduction in the bond between the tire chips and mixture, which leads to increase in the weight loss of mixture incorporated with higher rubber content.

The review of preceding literature evident that the adequate research has not yet been carried out on strength and durability characteristics of the cement stabilized clay incorporated with waste crumb rubber. The modified proctor tests were conducted in conformity with IS : 2720 (1983) to obtain the maximum dry density (MDD) and optimum moisture content (OMC) of the composite prior to unconfined compressive strength and durability tests.

\section{Materials Used}

\subsection{Soil}

The soil sample was taken Jaipur city in India. Some physical properties such as Atterberg limits, specific gravity, maximum dry density and optimum moisture content of the soil were determined in conformity with Indian Standards. Table 1 illustrates the results of the tests. The soil is classified as CL (clay with low plasticity) according to the Indian Standard Soil Classification System IS : 1498 (1970). The clay contains illite and quartz as predominant minerals along with some content of kaolinite. 
Table 1. Physical attributes of soil

\begin{tabular}{ccc}
\hline Soil properties & Indian Standard used & Values \\
\hline \hline Specific gravity & IS:2720 (Part 3)-1980 & 2.69 \\
Liquid Limit (\%) & IS:2720 (Part 5)-1985 & 34.2 \\
Plastic Limit (\%) & IS:2720 (Part 5)-1985 & 24.8 \\
Plasticity Index (\%) & IS:2720 (Part 5)-1985 & 9.4 \\
Maximum Dry Unit Weight (kN/m ${ }^{3}$ ) & IS:2720 (Part 8)-1983 & 16.35 \\
Optimum Moisture Content (\%) & IS:2720 (Part 8)-1983 & 20.89 \\
Swelling Pressure (kPa) & IS:2720 (Part 41)-1977 & 70.12 \\
\hline
\end{tabular}

\subsection{Crumb rubber}

The crumb rubber obtained from S\&J Granulate solution having the particle size between 0.8-2 $\mathrm{mm}$ was used in this investigation. Fig 1 reveals the gradation curve of crumb rubber. It shows that crumb consists of mainly sand-sized particles. Fig 2 illustrates the waste crumb rubber used in the investigation. The chemical composition as provided by the supplier is tabulated in Table 2 .

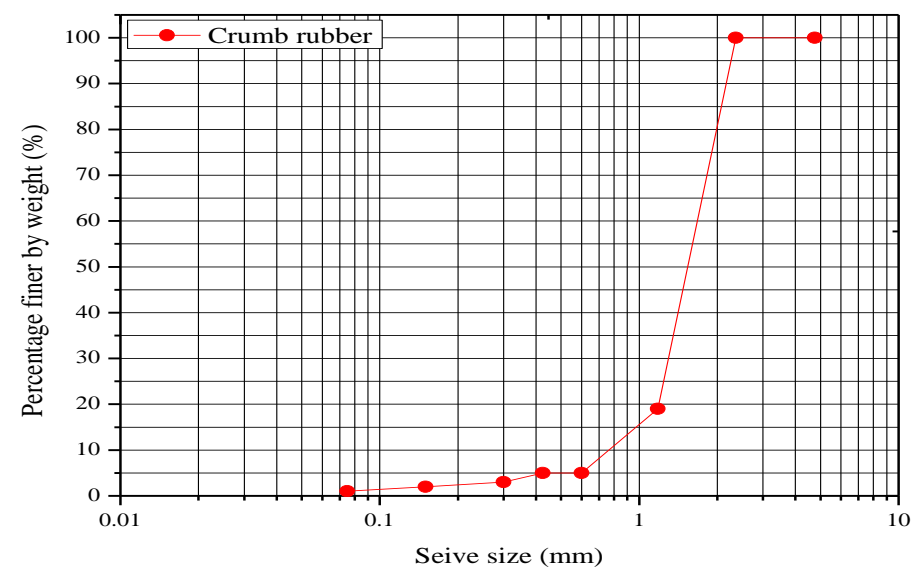

Fig 1 Gradation curve of crumb rubber

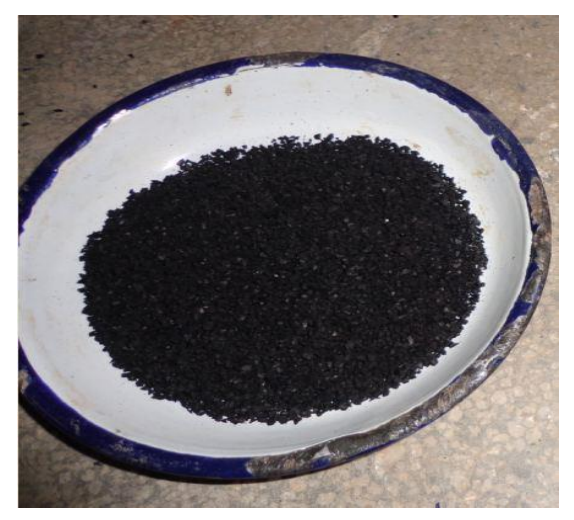

Fig 2. Crumb rubber used in the study

Table 2. Chemical composition of crumb rubber

\begin{tabular}{cc}
\hline Test & Results \\
\hline \hline Ash content, \% & 5.11 \\
Carbon black content, \% & 28.43 \\
Acetone extract, \% & 9.85 \\
Volatile matter, \% & 0.56 \\
Hydrocarbon content, \% & 56.05 \\
Polymer analysis & SBR \\
\hline
\end{tabular}

\subsection{Cement}

Ordinary Portland cement (OPC-43 grade) was used in this investigation. The physical properties determined in accordance with related Indian Standard. Table 3 illustrates the physical properties of cement.

Table 3. Physical properties of cement

\begin{tabular}{ccc}
\hline Properties & Indian Standard used & Values \\
\hline \hline Fineness & IS: $4301-1(1996)$ & 3.5 \\
Specific gravity, G & IS: $4301-11(1988)$ & 3.12 \\
Standard consistency, \% & IS: $4301-4(1988)$ & 39 \\
Initial setting time, minutes & IS: $4301-5(1988)$ & 35 \\
Final setting time, minutes & IS: $4301-5(1988)$ & 600 \\
Soundness (Expansion, mm) & IS: $4301-3(1988)$ & 4 \\
\hline
\end{tabular}




\section{Experimental Procedure}

\subsection{Proportion of ingredient and Preparation of mixture}

The soil sample obtained from the field was first air-dried and then pulverized to crush the lumps. The soil was mixed with crumb rubber and cement ranged from $2.5 \%-10 \%$ and $3 \%-6 \%$ by the weight of soil respectively. The general expression for the total dry weight (W) of claycement -crumb rubber mixture is:

$\mathbf{W}=\mathbf{W}_{\mathrm{S}}+\mathbf{W}_{\mathrm{C}}+\mathrm{W}_{\mathrm{R}}$

Where: $W_{S}, W_{C}$, and $W_{R}$ is the weight of soil, cement, and crumb rubber respectively.

Table 4 illustrates the details of mixtures and their proportions by dry weight on which the unconfined compressive strength and wetting-drying durability tests were conducted. For the sake of convenience and better understanding of the results, the codification of the mixes is used. The symbol S is used for clayey soil. $\mathrm{C} 1$ and $\mathrm{C} 2$ denote the $3 \%$ and $6 \%$ cement content. Similarly, R1, R2, R3, and R4 notation indicates $2.5 \%, 5.0 \%, 7.5 \%$ and $10.0 \%$ crumb rubber content, respectively. The required quantities of clayey soil and crumb rubber were mixed together in a laboratory mixer and stored in air tight plastic bags. Cement was incorporated at the time of formation of samples for unconfined compressive strength and durability tests. Then, as per the optimum moisture content obtained from modified proctor test for each mix, the required amount of water was added. Special care was taken for the homogeneity and uniformity of the mixes at each stage of mixing.

Table 4. Test mixtures and soil, rubber, and cement percentages

\begin{tabular}{|c|c|c|c|c|c|c|c|c|c|c|}
\hline \multirow{2}{*}{ Sample } & Soil & Rubber & \multirow{2}{*}{ Sample } & Soil & Rubber & Cement & \multirow{2}{*}{ Sample } & Soil & Rubber & Cement \\
\hline & \multicolumn{2}{|c|}{ Percentage (\%) } & & \multicolumn{3}{|c|}{ Percentage (\%) } & & \multicolumn{3}{|c|}{ Percentage $(\%)$} \\
\hline$S$ & 100 & 0 & C1 & 97 & 0 & 3 & $\mathrm{C} 2$ & 94 & 0 & 6 \\
\hline $\mathrm{R} 1$ & 97.5 & 2.5 & C1R1 & 94.5 & 2.5 & 3 & C2R1 & 91.5 & 2.5 & 6 \\
\hline $\mathrm{R} 2$ & 95 & 5 & C1R2 & 92 & 5 & 3 & $\mathrm{C} 2 \mathrm{R} 2$ & 89 & 5 & 6 \\
\hline R3 & 92.5 & 7.5 & C1R3 & 89.5 & 7.5 & 3 & C2R3 & 86.5 & 7.5 & 6 \\
\hline $\mathrm{R} 4$ & 90 & 10 & C1R4 & 87 & 10 & 3 & $\mathrm{C} 2 \mathrm{R} 4$ & 84 & 10 & 6 \\
\hline
\end{tabular}

\subsection{Test conducted}

\subsubsection{Compaction test}

During design of an engineered fill, testing performed to determine shear, consolidation, permeability, or other properties requires test specimens to be prepared by compacting the soil at a prescribed molding water content to obtain a predetermined unit weight. Compaction of soils increases their density, shear strength, bearing capacity but reduces their void ratio, porosity, permeability, and settlements. The modified Proctor tests were conducted on the various combinations as illustrated in the table 4 to determine the maximum dry density (MDD) and optimum moisture content of the mixtures as per IS : 2720 (Part VIII)-1983. The compaction on each sample was completed within 20 minutes of completion of mixing.

\subsubsection{Unconfined compressive strength test}

The unconfined compression strength test is used to determine the cohesion and shear strength of soil. It is an index for checking the short-term stability of foundation and slopes. It was carried out on various combinations as presented in table 4. Unconfined compressive strength tests were carried out in accordance with IS : 2720 (1991) on the specimens of $38.1 \mathrm{~mm}$ dia. and 76.2 mm length prepared at the maximum dry density (MDD) and optimum moisture content (OMC) of modified Proctor by static compaction method. The cylindrical mould of size $38 \mathrm{~mm}$ diameter and $76 \mathrm{~mm}$ length, with additional detachable collars were used to prepared the specimens by compressing the mould statically under uniform rate of deformation of $1.25 \mathrm{~mm} / \mathrm{min}$ approximately till the specimen just reached the desired dimension as per IS : 4332 (1968). The 
specimens were then extracted by using sample extractor. After that samples were wrapped in the air tight polythene bags and kept in a humidity controlled room $27 \mathrm{oC}$ temperature and $96 \%$ humidity) for a curing period of 7, 14, and 28 days (as shown in Fig 3(a)). The samples obtained after completion of age of curing were placed in strain-controlled unconfined compressive strength apparatus and axial strain was applied at a rate of $1 \mathrm{~mm} / \mathrm{min}$ (as revealed in Fig 3(b)).

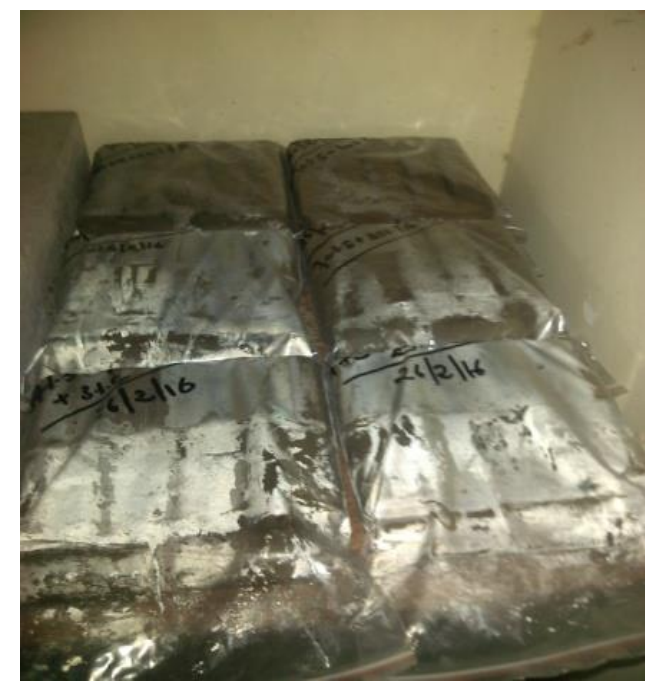

(a)

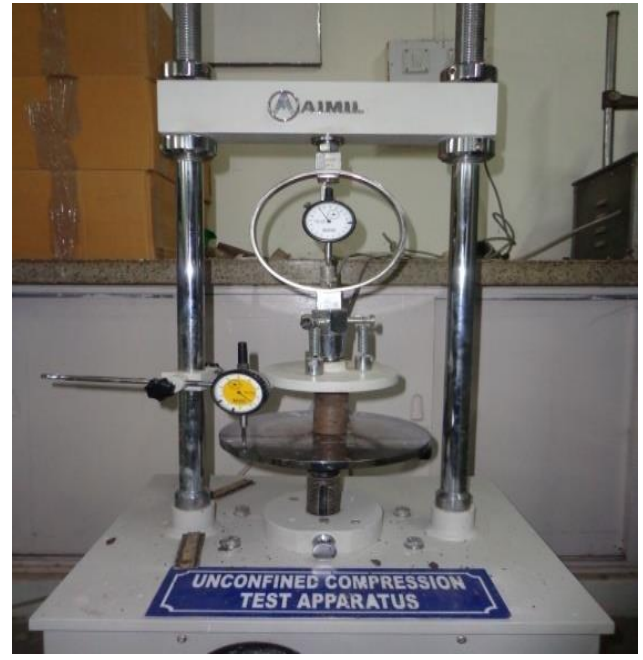

(b)

Fig 3. (a) Specimens cured in humidity-controlled room (b) Setup for unconfined compressive strength tests

\subsubsection{Wetting-Drying Durability test}

The most crucial parameter to assess the suitability of any construction material is its durability for their use. The durability of cement -stabilized soils can be predicted by tube suction, 7-day unconfined compression strength, wetting-drying cycles and freezing-thawing cycle's tests. In this investigation, the traditional wetting -drying cycles tests were performed in conformity with IS : 4332 (1968) for securing the durability of the proposed composite in the adverse environmental conditions. The test specimens of volume 1000cc were prepared at their MDD and OMC and extracted from the mould by using sample extractor as shown in Fig 4(a) and 4(b). The samples so obtained were wrapped in the plastic sheet and placed in the humidity control room for curing period of 7, 28, 90, and 180 days (as revealed in Fig 4(c)). After the completion of the curing age, the specimens were exposed to twelve alternate wetting and drying cycles. Each wetting and dry cycle consisted of 5 hours of soaking in potable water at room temperature (as illustrated in Fig 4(d)) and 42 hours of heating in an oven at $70^{\circ} \mathrm{C}$ (as shown in Fig 4(e)).

Total four specimens for each combination were prepared and out of four specimens, two specimens were brushed parallel to the longitudinal axis of specimens to measure the weight loss upon scratching after each wet and dry cycle. The rest two specimens were used to determine the change in the dimensions and moisture content. According to Portland Cement Association (PCA) and Bhattacharja and Bhatty (2003), the weight loss of the specimens after 12 cycles of wetting and drying should not exceed $14 \%$ for granular soils of low plasticity and $7 \%$ for cohesive clays of their original mass. However, these recommendations of PCA were found to be too stringent as per some other studies. $20 \%$ and $30 \%$ loss in mass have been recommended for the cement stabilized materials to be used as base, sub-base, and shoulder for construction of roads as per IRC: SP: 89 (2010). 


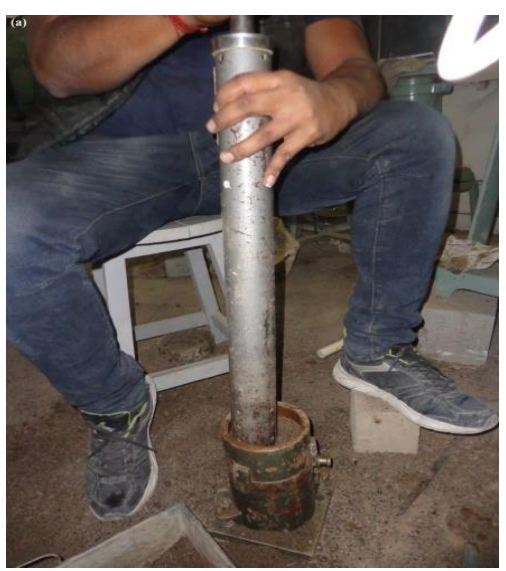

(a)

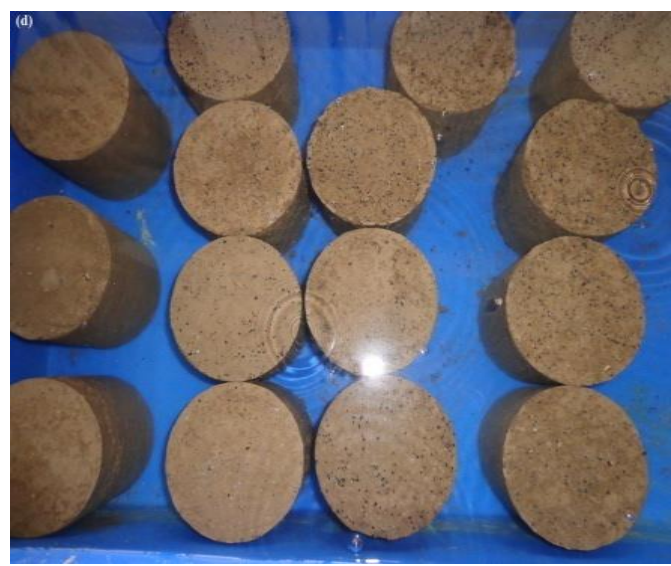

(d)

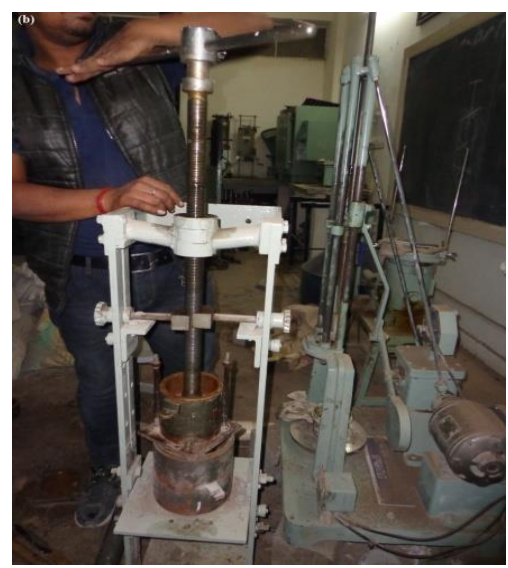

(b)

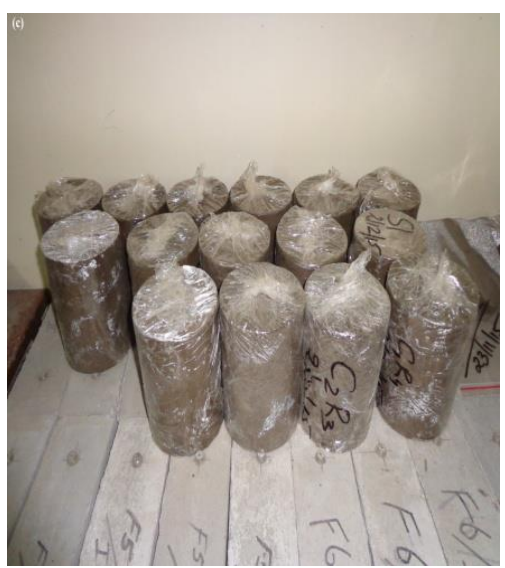

(c)

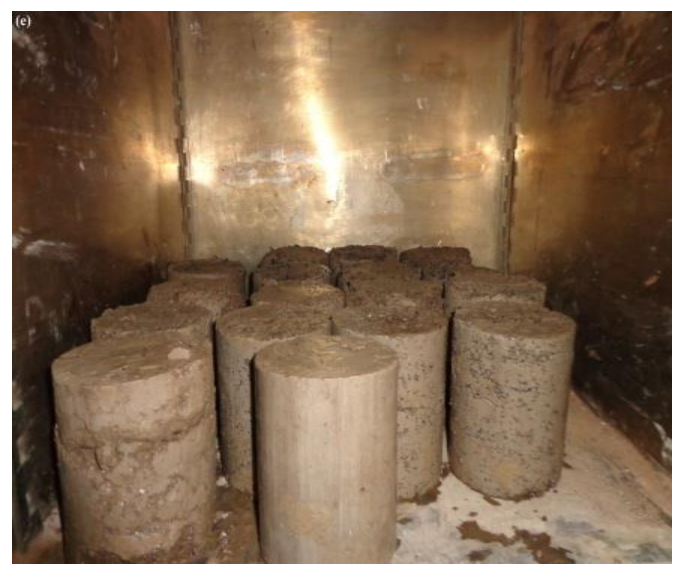

(e)

Fig 4. The sequential steps of the preparation of samples for wetting and drying durability testing from: (a) to (e).

\subsubsection{Mineralogical and Microscopical Studies}

The most probable phases of the mineral present in $\mathrm{C} 1$ and $\mathrm{C} 2$ after curing were determined by the X-ray diffraction studies. A PANalytical X'pert PRO Powder diffractometer (Type 11141934) having copper electrodes that act as the source of radiation ( $\mathrm{Cu}$-Kó radiation, $40 \mathrm{kV}-40 \mathrm{~mA}$ ) was used. The specimens were scanned from $2 \theta=10.020$ to 79.9800 with step scanning at $0.02^{\circ} / 0.5$ s. The mineralogical phases present in the mixtures were identified by X'pert High score equipped with JCPDS PDF-2 database (ICDD 2003).

The particle morphology of mixes was analyzed from micrographs obtained with the aid of scanning electron microscope (Nova Nano FE-SEM 450 (FEI)). The samples were prepared in the same way as for the UCS tests. They were cured for 28 days and then oven dried. The freshly cut specimen of $1 \mathrm{~cm} \times 1 \mathrm{~cm} \times 1 \mathrm{~cm}$ were viewed under SEM to establish the change in the microstructure due to addition of cement and rubber in the mixes.

\section{Results and Discussion}

\subsection{Compaction test}

Table 5 shows the results of modified Proctor test conducted on the various mixtures as illustrated in table 4 . The inclusion of rubber in the clayey soil leads to lowering in the maximum dry density (MDD) of clay as indicated in table 5. For example, the maximum dry density of the clay is $16.35 \mathrm{kN} / \mathrm{m}^{3}$, which reduces to $16.14 \mathrm{kN} / \mathrm{m}^{3}$ to $14.82 \mathrm{kN} / \mathrm{m}^{3}$ with the addition of $2.5 \%$ to 
$10 \%$ rubber content. The decrease in the density of the clay is the possibility due to the reduction in clay content and low specific gravity of rubber. The introduction of cement in the rubberized clay results into the further reduction in MDD of a mixture. For example, for sample $\mathrm{R} 2$, the MDD is $15.67 \mathrm{kN} / \mathrm{m}^{3}$, which decreases to $15.57 \mathrm{kN} / \mathrm{m}^{3}$, and $15.15 \mathrm{kN} / \mathrm{m}^{3}$ respectively for sample C1R2 and C2R2. The decrease in the MDD of the mixture with the inclusion of cement may be due to increasing in the void ratio resulted by the Base Exchange aggregation and flocculation phenomenon. The optimum moisture content (OMC) of the clay is $20.89 \%$, which reduces to $20.45 \%, 19.38 \%, 18.96 \%$, and $18.38 \%$ with the addition of $2.5 \%, 5 \%, 7.5 \%$, and $10 \%$ rubber, respectively. The reduction in the $\mathrm{OMC}$ of clay with the incorporation of rubber is the result of low water absorption capacity of rubber. However, the addition of cement in the rubberized clay increased the OMC of the mixtures. The water content of sample R2 is $19.38 \%$, which enhances to $19.58 \%$ and $19.78 \%$ with the addition of $3 \%$ and $6 \%$ cement in the mix. The additional water required for the hydration process of cement may be attributed as the reason behind the increase in $\mathrm{OMC}$ of the mixtures.

Table 5. Maximum dry density and Optimum moisture content of the mixtures.

\begin{tabular}{ccccccccc}
\hline Sample & $\begin{array}{c}\text { MDD } \\
\left(\mathrm{kN} / \mathrm{m}^{3}\right)\end{array}$ & $\begin{array}{c}\text { OMC } \\
(\%)\end{array}$ & Sample & $\begin{array}{c}\text { MDD } \\
\left(\mathrm{kN} / \mathrm{m}^{3}\right)\end{array}$ & $\begin{array}{c}\text { OMC } \\
(\%)\end{array}$ & Sample & $\begin{array}{c}\text { MDD } \\
\left(\mathrm{kN} / \mathrm{m}^{3}\right)\end{array}$ & $\begin{array}{c}\text { OMC } \\
(\%)\end{array}$ \\
\hline \hline S & 16.35 & 20.89 & C1 & 16.25 & 21.28 & C2 & 16.18 & 21.86 \\
R1 & 16.14 & 20.45 & C1R1 & 15.84 & 20.35 & C2R1 & 15.65 & 20.56 \\
R2 & 15.67 & 19.38 & C1R2 & 15.57 & 19.58 & C2R2 & 15.15 & 19.78 \\
R3 & 15.15 & 18.96 & C1R3 & 15.05 & 19.05 & C2R3 & 14.89 & 19.58 \\
R4 & 14.82 & 18.38 & C1R4 & 14.64 & 18.58 & C2R4 & 14.47 & 18.78 \\
\hline
\end{tabular}

\subsection{Unconfined compressive strength test}

\subsubsection{Stress-strain response}

The stress-strain response of the clay mixed with $2.5 \%-10 \%$ crumb rubber is shown in Fig 5(a). The stress-strain curves for the rubberized clay stabilized with $3 \%$ and $6 \%$ cement cured for 28 days are shown in Figs 5(b) and 5(c). A study of Fig 5(a) reveals that the peak axial stress of clay mixed with rubber increases marginally up to $5 \%$ inclusion of crumb rubber, thereafter it starts decreasing. For example, for clay specimen $\mathrm{S}$, the peak axial stress is $60.62 \mathrm{kPa}$, which increases to $61.87 \mathrm{kPa}$ and $63.71 \mathrm{kPa}$, when $2.5 \%$ and $5.0 \%$ crumb rubber is incorporated in it and decreases to $55.67 \mathrm{kPa}$ and $48.47 \mathrm{kPa}$, with the inclusion of $7.5 \%$ and $10.0 \%$ rubber content. These results are found similar to Srivastava et al. (2014).

Exanimation of Figs 5(b) and 5(c) reveal that the peak axial stress of cement stabilized clay increases with increase in the cement content and decreases with increase in the rubber content. For example, the peak axial stress of specimen C1R1 is $201.89 \mathrm{kPa}$ which increases to 366.13 $\mathrm{kPa}$ for specimen C2R1 and the peak axial stress of specimen C1R1 is $201.89 \mathrm{kPa}$, which decreases to $168.96 \mathrm{kPa}$ and $122.14 \mathrm{kPa}$ respectively for specimen C1R3 and C1R4. The decrease in the peak axial stress may be attributed to the (i) entrapping of air because of non-polar nature of rubber (Guleria and Dutta, 2011; Wang and Song, 2015), (ii) soft aggregate like behavior of rubber (Guleria and Dutta, 2011), (iii) negligible load carrying capacity of crumb rubber (Wang and Song, 2015).

The failure strain of clay stabilized with $3 \%$ and $6 \%$ cement is $3.29 \%$ and $4.61 \%$ respectively, which is much smaller than uncemented rubberized clay. A marked stiffness and brittleness is observed in cement-stabilized clay, which is similar to the observation made by Tang et al. (2007) and Yadav and Tiwari (2016). With the inclusion of rubber in the cement-stabilized clay the sudden drop of strength after attaining peak stress becomes gradual. The incorporation of rubber reduces the brittleness of the response of cement-stabilized clay and changes the behavior of the composite from brittle to ductile by lowering the rate of loss of post-peak strength. It is possibly due to (i) the lower young's modulus of elasticity of the crumb rubber as compared to cemented clay specimens (Guleria and Dutta, 2011), (ii) tire chips are elastic in nature and prevented from generating and growing cracks by the elastic reaction, which is 
generated from tire chips during compression (Yoshio et al., 2008), (iii) elastic compression of the crumb rubber, which leads to the strain softening after reaching the peak axial strain (Kim and Kang, 2013), (iv) crumb rubber acts as a reinforcement which enhances soil ability to restrain cracking (Shahin and Hong, 2010). The failure strain of the cement stabilized clay containing rubber contain up to $5 \%$ is found to be more than the other percentages of rubber content. For example, the failure strain of specimen C1R2 is $5.92 \%$, where as for the specimens C1R1, C1R3 and C1R4 are 3.29\%, 5.26\%, and 4.61\% respectively.
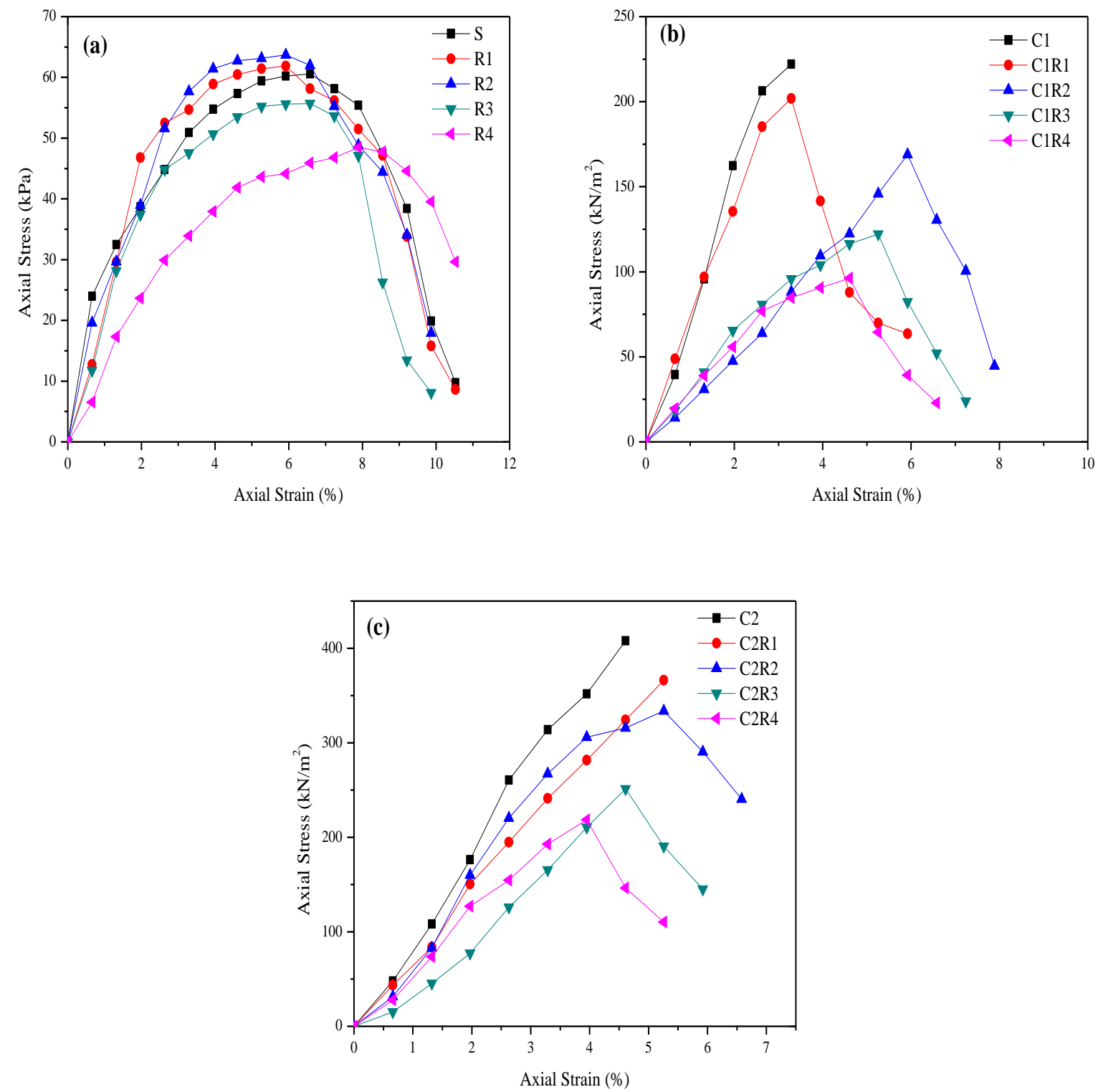

Fig 5. Stress-strain response of clayey soil samples containing (a) $2.5 \%$ to $10 \%$ rubber; (b) containing $2.5 \%$ to $10 \%$ rubber and $3 \%$ cement after 28 days of curing; (c) containing $2.5 \%$ to $10 \%$ rubber and $6 \%$ cement after 28 days of curing.

\subsubsection{Energy Absorption Capacity}

The energy absorption capacity is defined as an area of the stress-strain curve upto maximum axial stress at failure as indicated in Fig 6(a). Fig 6(b) show the variation of energy absorption capacity of clayey soil mixed with cement and waste crumb rubber with age of curing. The energy absorption capacity of the rubberized clay containing $6 \%$ cement content is found to be more in comparison with rubberized clay containing $3 \%$ cement at all curing period. For example, 28 days cured specimen of C1R1 is $3.73 \mathrm{~kJ} / \mathrm{m}^{3}$, which increases to $9.63 \mathrm{~kJ} / \mathrm{m}^{3}$ for 
specimen C2R1. The energy absorption capacity of the clay- crumb rubber mixtures stabilized with $3 \%$ cement decreases with the incorporation of more than $5 \%$ rubber content. For example, the energy absorption capacity of specimen C1R2 is $4.64 \mathrm{~kJ} / \mathrm{m}^{3}$, which decreases to $3.82 \mathrm{~kJ} / \mathrm{m}^{3}$, and $2.733 \mathrm{~kJ} / \mathrm{m}^{3}$ for specimen C1R3 and C1R4 respectively. Whereas the energy absorption capacity of mix C2R1 and C2R2 is found almost similar i.e. $9.63 \mathrm{~kJ} / \mathrm{m}^{3}$ and $9.40 \mathrm{~kJ} / \mathrm{m}^{3}$, and decreases for specimen C2R3 and C2R4.With prolongation of the curing period, the energy absorption capacity of the composites increases. For example, 7 days cured specimen of C2R1 has energy absorption capacity of $8.21 \mathrm{KJ} / \mathrm{m}^{3}$, which increases to $9.03 \mathrm{~kJ} / \mathrm{m}^{3}$ and $9.87 \mathrm{~kJ} / \mathrm{m}^{3}$ with an increase in the curing period to 14 , and 28 days.
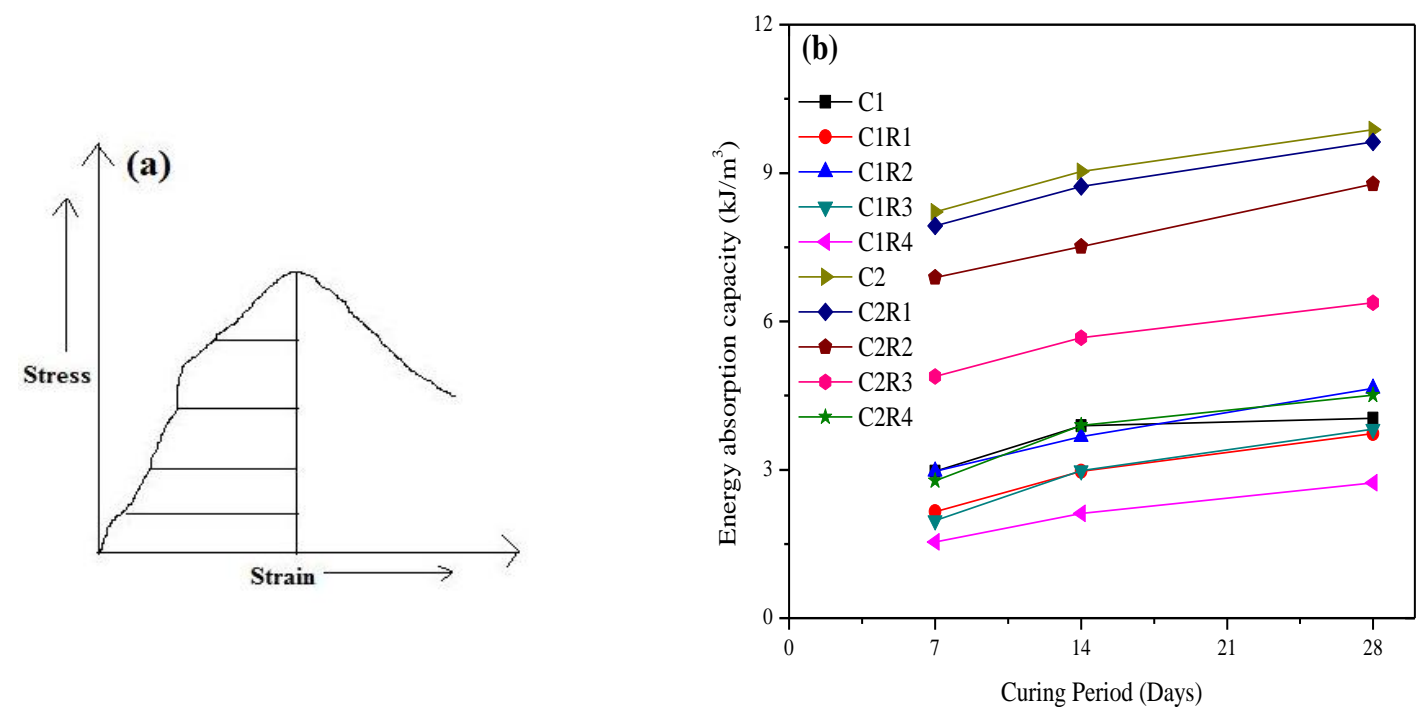

Fig 6. (a) Schematic diagram for energy absorption capacity (b) Energy absorption capacity - curing period of the mixes.

\subsubsection{Unconfined compressive strength}

The unconfined compressive strength test results of cement stabilized clay mixed with different crumb rubber content and cured for 7, 14 and 28 days are shown in Figs 7(a) and 7(b). The unconfined compressive strength of the clay increases with the addition of cement. For example, 28 days UCS of the clay containing $3 \%$ cement (specimen C1) is $222.05 \mathrm{kPa}$, which is approximately 3.7 times greater than clay (specimen S). It is due to the formation of hydration product in the cemented clay mixture, which leads to the strengthening of the specimens. Similarly, the unconfined compressive strength of the clay containing $6 \%$ cement is found to be approximately 6.73 times more than clay specimens. The unconfined compressive strength of the clay increases with the increase in cement content. It is due to the increase in relative cement per grain contacts points. The unconfined compressive strength of the cement-stabilized clay incorporated with crumb rubber decreases with the increase in rubber content. For example, the UCS of 28 days cured the specimen C1 is $222.05 \mathrm{kPa}$, which decrease to $168.96 \mathrm{kPa}, 122.14 \mathrm{kPa}$ and $96.22 \mathrm{kPa}$ for specimens C1R2, C1R3 and C1R4 respectively. Similarly, the UCS of specimen C2 is $405.07 \mathrm{kPa}$, which decreases to $333.85 \mathrm{kPa}, 251.36 \mathrm{kPa}$ and $217.17 \mathrm{kPa}$ for specimens C2R2, C2R3 and C2R4 respectively. These observations are found contrary to results reported by Hambirao and Rakaraddi (2014). Fig 7 reveals that UCS of the cement stabilized clay containing crumb rubber increases with prolonging the age of curing. For example, 7 days UCS of specimens C2R2 is $248.40 \mathrm{kPa}$, which increased to a value of $321.30 \mathrm{kPa}$ and $333.85 \mathrm{kPa}$ after 14 days, and 28 days of curing respectively. It is possibly due to the formation of more hydration products with prolongation of the age of curing. The rate of loss of unconfined compressive strength of cement stabilized clayey soil containing rubber content more than $5 \%$ is found more. For example, a loss of $19.4 \%$ in UCS is observed for specimen C1R2 as compared to C1R1 and 
38.33\% for specimen C1R3 as compared to C1R2. At higher rubber content, the rate of loss of strength is more, which is possible due the (i) governances of the interaction between the rubber to rubber particle, rather than rubber to cemented clay particles (Cabalar and Karabash, 2015); (ii) difficulty in packing of lightweight rubber particles at higher rubber content create voids (Benazzouk et al., 2007); (iii) sliding of the rubber particle, which is not restricted by the interfacial mechanical interaction between rubber and cemented clay particles; (iv) loss of friction and bonding in the mixtures (Kim and Kang, 2013).
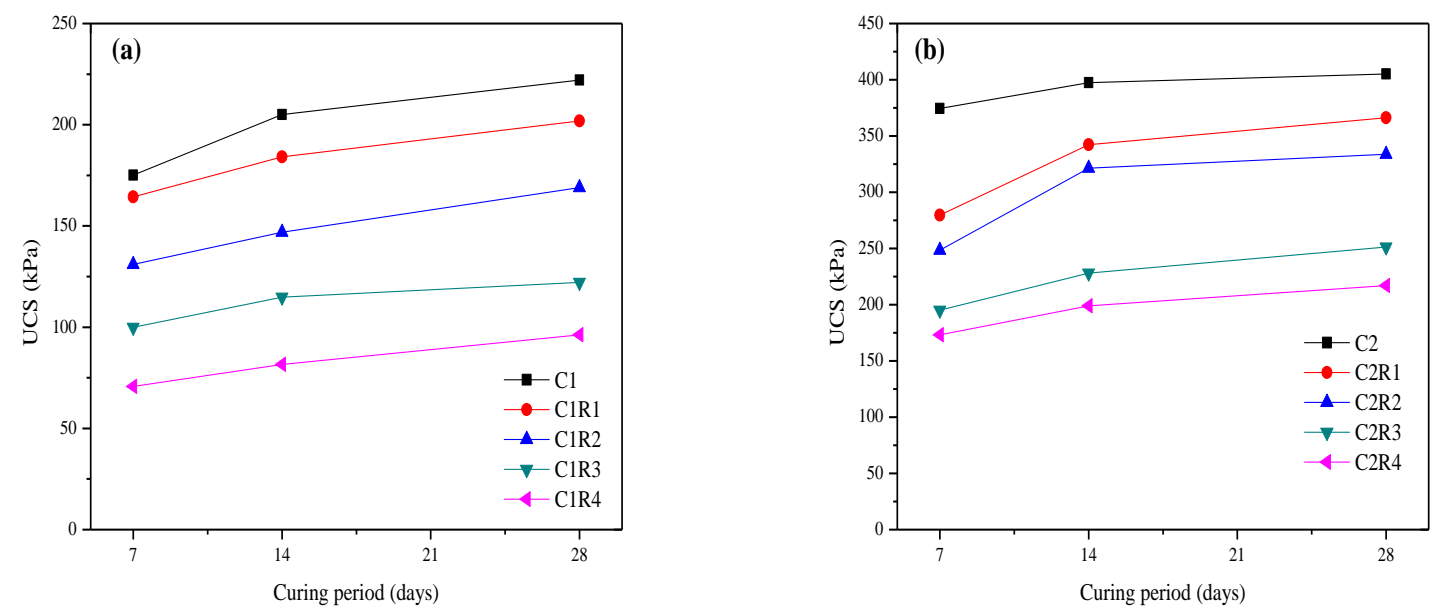

Fig 7. Unconfined compression test of the combination.

\subsubsection{Cracking Pattern}

The vertical cracks were observed in the cement-stabilized specimens as evident from Fig 8(a), which was responsible for the brittle behavior and no post-peak strength of the mix. The cracking pattern of cement-stabilized clayey soil specimens incorporated with crumb rubber was observed to have multiple or staggered cracks as shown in Fig 8(b) and 8(c). These multiple/staggered cracks enable the specimen to bear the post-failure load. The multiple cracking is possibly due to (i) lower young modulus of rubber compared to cemented clay (Guleria and Dutta, 2012), (ii) development of elastic reaction under the compression load in crumb rubber (Yoshio et al., 2008). It empowers the specimens to have high deformability and energy absorption capacity.
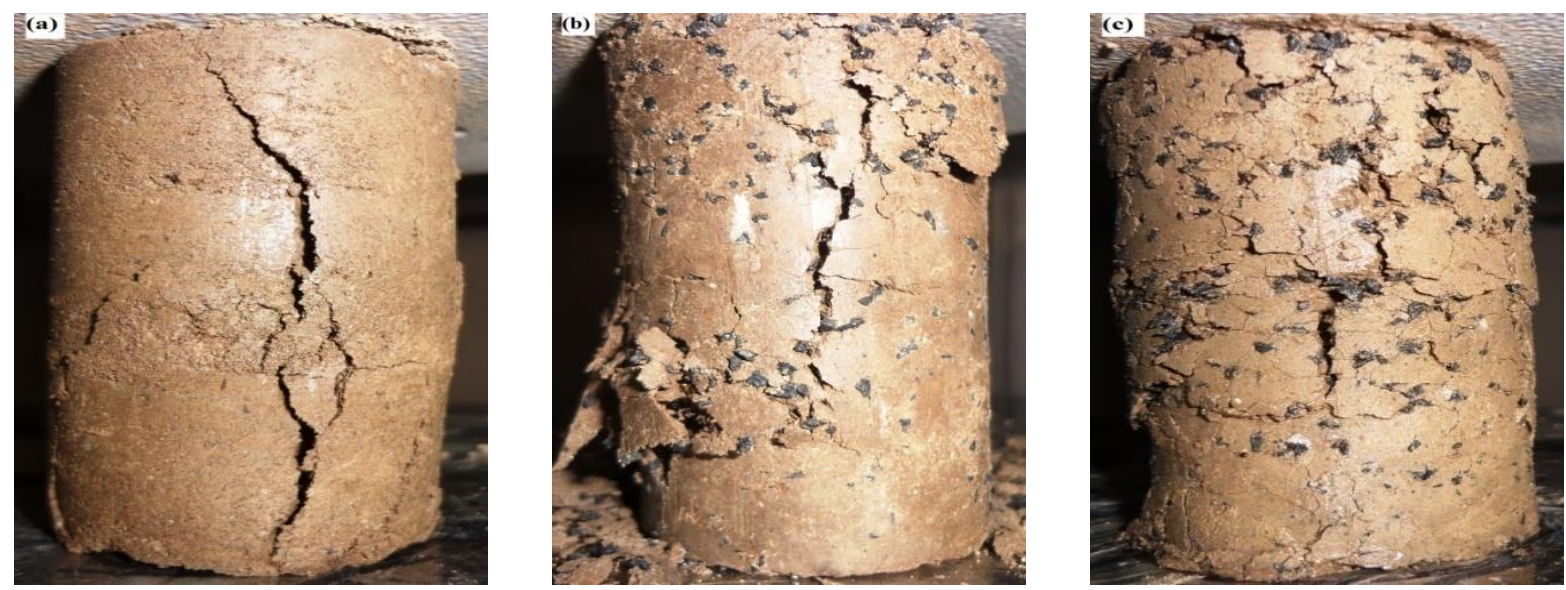

Fig 8. (a) Vertical cracking in cemented clay specimen, (b) \& (c) Multiple/staggered cracking in cemented clay specimen containing rubber. 


\subsection{Wet-dry Durability test}

The continuous wetting and drying impact the serviceability and performance of rubberized cemented clay. The durability of the composite depends upon the pore structure, tensile strength, inter-particle friction and cohesion of the materials. The test result of the wet-dry durability in term of weight loss for 7, 28, 90, and 180 days cured specimens are plotted against the number of cycles in Fig 9. Clay-crumb rubber samples were unable to resist the first cycle of the process and disintegrated completely. Similarly, 7 days cured samples of clay containing 3\% cement and $2.5 \%-10.0 \%$ crumb rubber could not maintain the volumetric integrity and fail, along with samples of clay containing $6 \%$ cement and $7.5 \%$ and $10 \%$ crumb rubber before the completion of wet and dry process as illustrated in Fig $9(\mathrm{a})$. While rubberized clay containing $6 \%$ cement and $2.5 \%$ and $5 \%$ crumb rubber is successful to endure the complete 12 cycles of wetting and drying. On prolonging the curing period of the specimens before subjected to wet and dry cycle, all the specimens are able to survive the complete process of durability test (except for C1R3, C1R4 and C2R4 specimens) as shown in Fig 9(c) and 9(d).
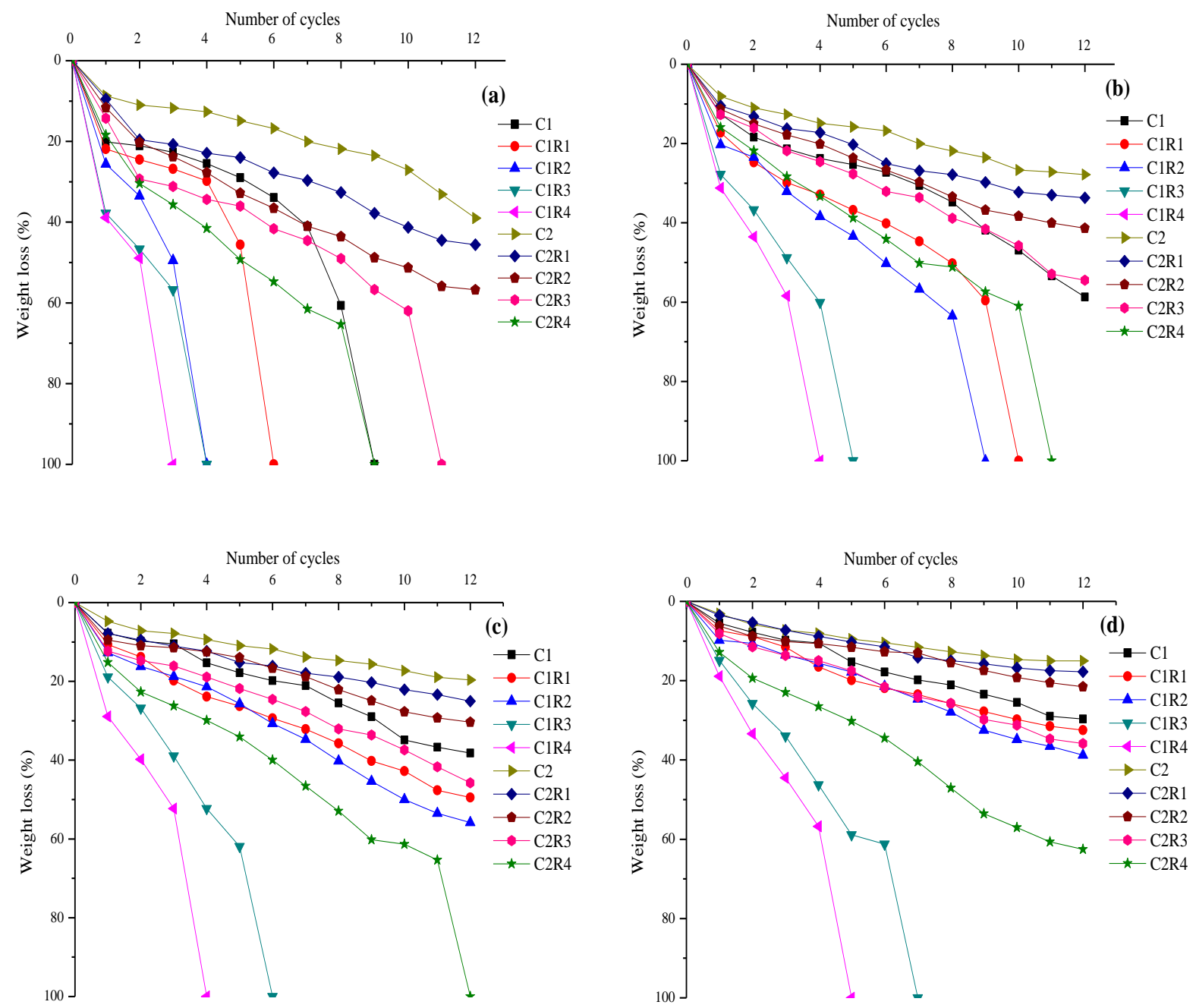

Fig 9. Weight loss- Number of cycles of (a) 7 days, (b) 28 days, (c) 90 days, and (d) 180 days cured specimens.

Fig 10 shows the variation of weight loss of the specimens with the curing period after completion of 12 wetting and drying cycles. The weight loss of clay mixed with cement decreases with the increase in cement content. For example, for 180 days cured specimen C1, the weight loss is $29.68 \%$, which decreases to $15.02 \%$ for the specimen C2. The weight loss of cemented clay incorporated with rubber increased consistently with the increasing rubber content. For 
example, the weight loss of 90 days cured specimen C1 is $38.20 \%$ which increased to $49.47 \%$ and $55.84 \%$ for the specimen C1R1 and C1R2 respectively. The disparate thermal elaboration between rubber and cemented clay during the drying cycle causes the deficiency in the bond strength between crumb rubber and cemented clay. Further, the abrasive action of wire brush which was applied after the drying cycle leads to void formation and increases the weight loss (Guleria and Dutta, 2013). Fig 10 shows that the weight loss of specimens containing 3\% cement and varying percentages of rubber is higher than that of specimens containing $6 \%$ cement and varying percentages of rubber. For example, the weight loss of $49.47 \%$ and $55.84 \%$ for the specimens C1R1 and C1R2 at 90 days decreased to $25.0 \%$ and $30.38 \%$ for the specimens C2R 1 and C2R2 respectively. The weight loss of rubberized cemented clay specimens decreases with the prolongation of curing period. For example, a weight loss of $45.6 \%$ for the specimen C2R1 cured for 7 days decreased to $33.67 \%, 25.0 \%$, and $17.77 \%$, respectively with the prolongation of the curing period to 28,90 , and 180 days.

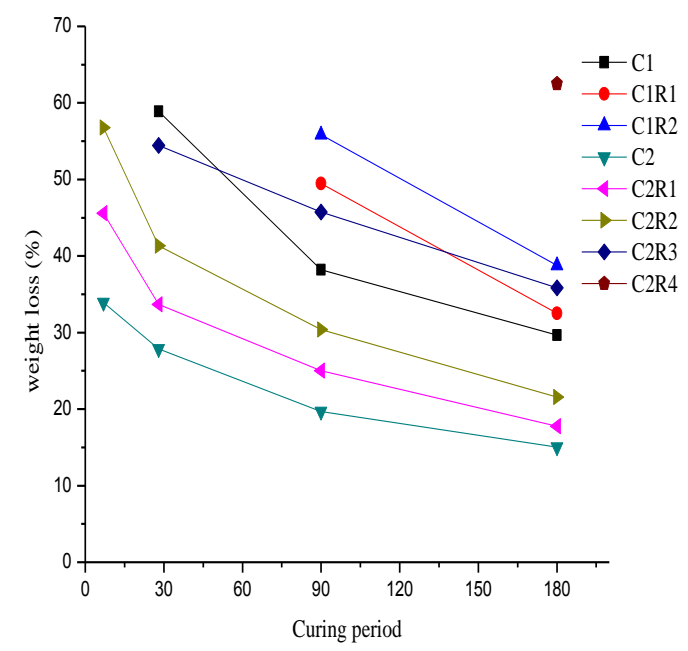

Fig 10. Weight loss- curing period of the composites after completion of 12 wetting and drying cycles.

According to IRC: SP: 89 (2010), the weight loss up to $20 \%$ and $30 \%$ have been allowed during the wet-dry durability test for cement stabilized material to be used as base, sub-base, and shoulder for road construction. Only specimens C2, C2R1, and C2R2 satisfy this criterion of maximum allowable weight loss. Therefore, up to $5 \%$ inclusion of crumb rubber in clayey soil containing $6 \%$ cement is worthwhile from durability aspect. However, more research is required to address the recommendation of PCA for the use of proposed composite as road pavement material.
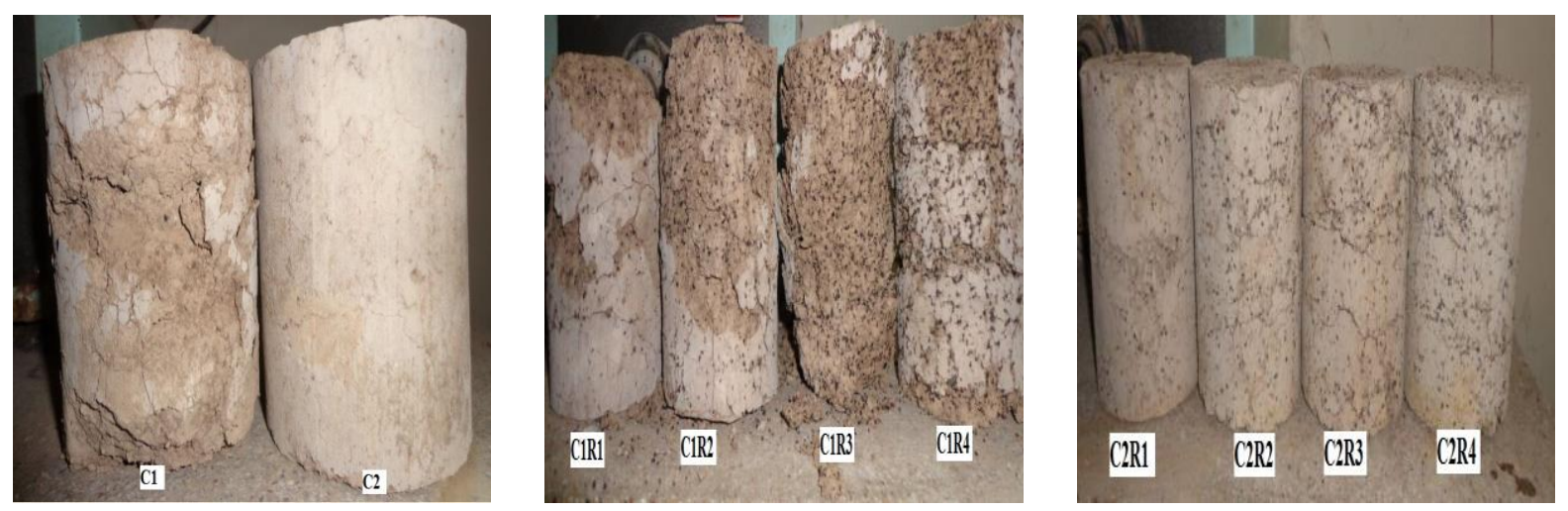

Fig 11. Photographs of the composite cured for180 days during wetting and drying cycles. 


\subsection{Mineralogical and Microscopical Studies}

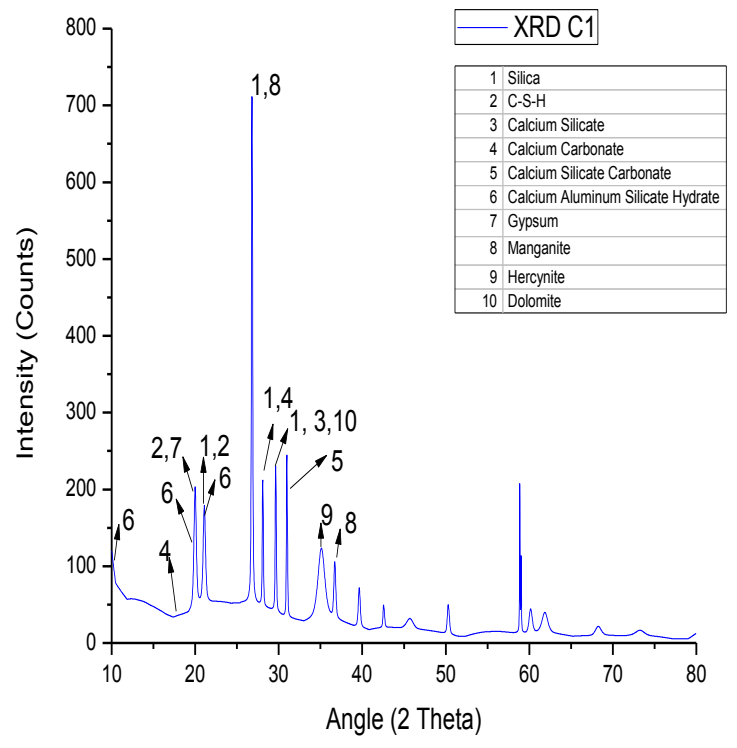

(a)

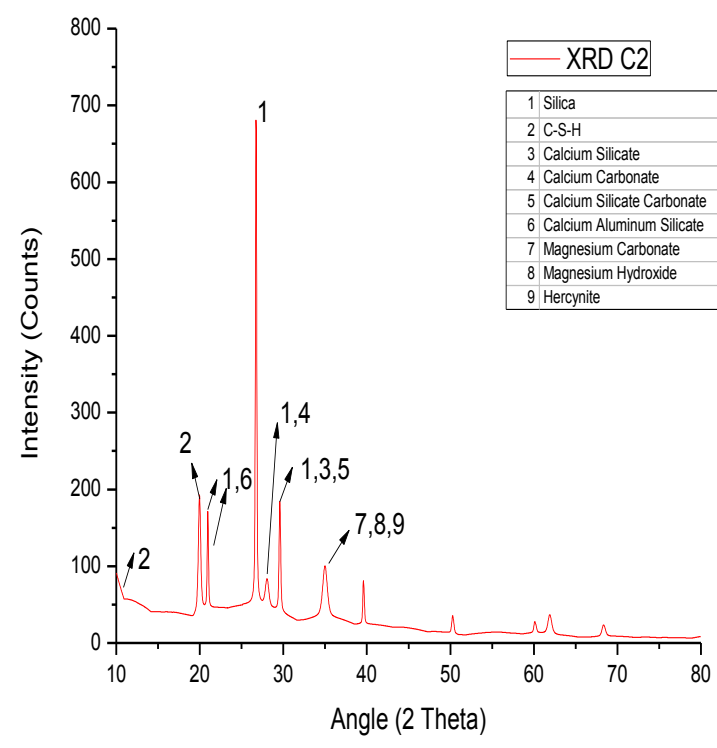

(b)

Fig 12. XRD pattern of (a) C1, and (b) C2 cured for 28 days.

Fig. 12(a) and 12(b) shows the XRD pattern of C1 and C2 after 28 days of curing. The crystalline phase present are identified from the peaks in the pattern. Due to the inclusion of cement in the clay, changes in the mineralogical composition of mixes are observed. Several new peaks of calcium silicate hydrate (C-S-H), calcium aluminium silicate hydrate, calcium carbonate, calcium silicate, calcium silicate carbonate, etc. are visualized. These new peaks confirm the cementing products of hydration and pozzolanic reactions between the clay and cement minerals. There is a reduction in the peaks intensity of quartz from 715.59 to 691.08 respectively, for C1 and C2 indicate the cementitious reactions taken place between the composite leading to the formation of hydration products. Kaolinite is completely exhausted which leads to the formation of cessation of the pozzolanic reaction and additional cementitious products. The formation of these cementitious products improved the strength of the composite by enhancing the binding action of cement matrix.

Fig. 13(a) - (e) shows the SEM images of the mixtures. The dark portions are assumed voids in the matrix and fibrous crystals indicate $\mathrm{C}-\mathrm{S}-\mathrm{H}$ gel. Due to compaction large clay cluster, reduces to small clusters, which lead to reduce the pore space as indicated in Fig. 13(a). Fig. 13(b) - (c) shows micrograph of cement-treated clay specimens (C1 and C2) after 28 days curing. The SEM images of $\mathrm{C} 1$ are similar to untreated soil sample because lesser amount of cement content as compared to soil mass. As the content of cement increases, the hydration product increases. The increase in the cementitious products fills the pores spaces and enhances the inter-cluster bonding strength as shown in Fig. 13(c). The reaction product formation could be clearly observed in the Fig. 13(d). The reaction product may be hydrated product like C-S-H and are most likely responsible for the increase in the strength of cement stabilized samples. At the interface of rubber and cement matrix, a gap can be visualized in Fig. 13(e) along with micro cracks in the C2R2 specimen. The poor interaction between rubber and cemented clay leads to cracking and ultimately results into reduction in strength of the composite. 


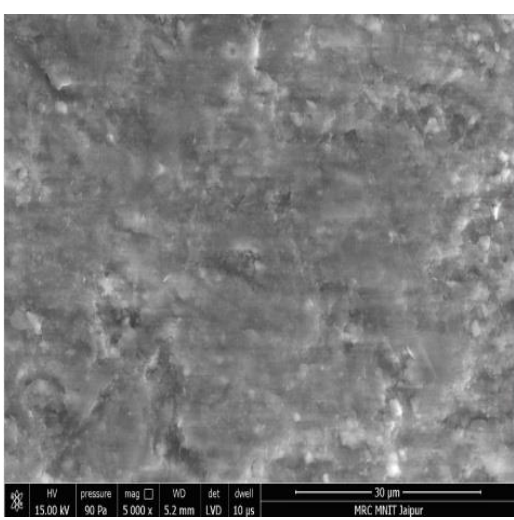

(a) Clay

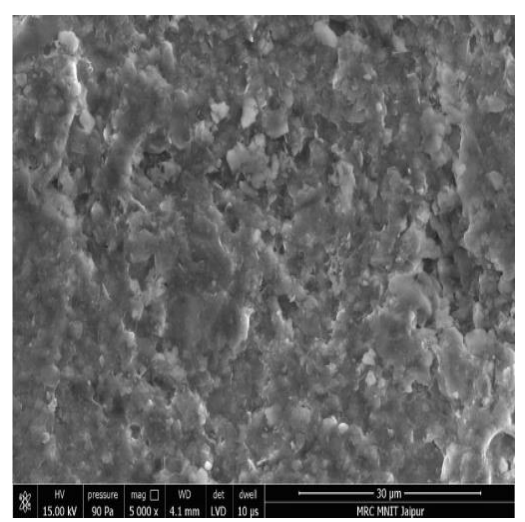

(b) C1 (after 28 days)

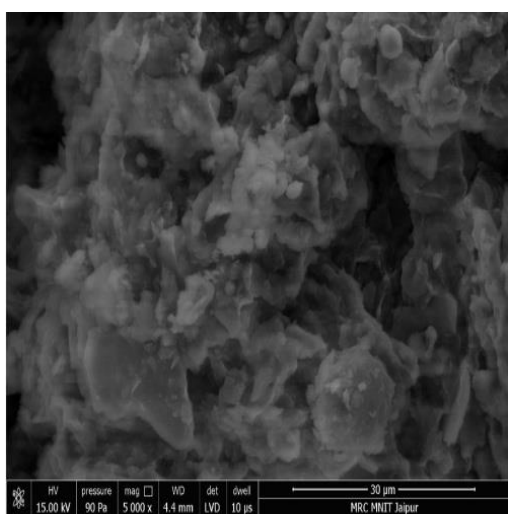

(c) C2 (after 28 days)

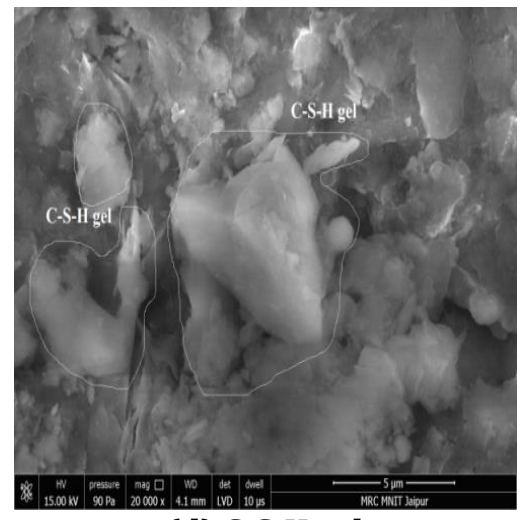

(d) C-S-H gel

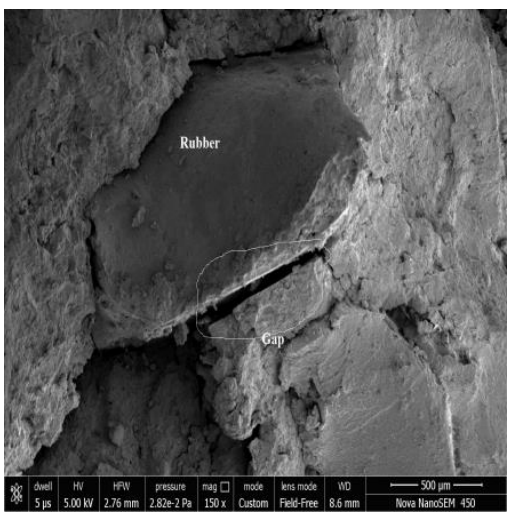

(e) C2R2 (after 28 days)

Fig 13. SEM of (a) Clay (b) C1 (c) C2 and (d) C-S-H gel (e) C2R2

\section{Conclusions}

In the present paper, unconfined compressive strength, and wet-dry durability characteristics of the clayey soil incorporated with crumb rubber and cement were investigated. The conclusions of the investigation are as follows:

1. Both maximum dry density and optimum moisture content of the clay decreases with the addition of crumb rubber, whereas inclusion of cement in the rubberized clay leads to decrease in the density and increase the optimum moisture content of the mixtures.

2. The inclusion of crumb rubber in the cement-stabilized clayey soil reduces the UCS. The decrease in UCS was on the higher side with the incorporation of rubber more than $5 \%$.

3. The brittle behavior of the cement-stabilized clay has prosperously overcome with the inclusion of rubber by lowering the rate of loss of post-peak strength.

4. The cement stabilized clay soil mixed with various percentages of crumb rubber has shown an increase in energy absorption capacity by incorporation of rubber content up to $5 \%$.

5. The clayey soil samples mixed with crumb rubber could not show enough durability and disintegrate during the first wet-dry cycle.

6. The weight loss of the clayey soil specimen mixed with cement can be decreased with the inclusion of the higher amount of cement and with the increasing the curing period.

7. The incorporation of rubber (2.5\% to $10 \%)$ increases the weight loss of cementstabilized clay.

8. The weight loss of 90 days cured specimen of clay incorporated with $6 \%$ cement and rubber content up to 5\% is observed closure to requirements of IRC:SP:89-2010. 
9. Calcium silicate hydrate (C-S-H), calcium aluminium silicate hydrate, calcium carbonate, calcium silicate, calcium silicate carbonate etc minerals are found in the $\mathrm{C} 1$ and $\mathrm{C} 2$ specimens from XRD analysis. The formation of cementation products became more dense and compact as cement content increases.

10. From the SEM images, the C-S-H gel formation is clearly seen in the cemented clayrubber mixture, which is the main governing force in the composite.

11. The presence of gap between the rubber and cemented clay is an indication of weak interfaces resulting into strength reduction in the composite.

The results of tests presented in this research paper have confirmed that the inclusion of crumb rubber and cement in the clayey soil effects unconfined compressive strength and wet-dry durability properties. The results reveal that the crumb rubber up to $5 \%$ can be significantly incorporate with cement-stabilized clayey soils. The proposed composite can be a good material for use in base, sub-base, and shoulder in road construction having low traffic volume and lightweight fill material behind the retaining wall. The enormous utilization of waste crumb rubber for improving geotechnical properties uncemented/cemented clay helps to solve the health and environmental problems associated with the disposal of this hazardous waste.

\section{References}

Akbulut, S., Arasan, S., Kalkan, E. (2007). Modification of clayey soils using scrap tire rubber and synthetic fibers. Appl. Clay Sci. 38, 23-32.

Al-Tabbaa, A., Blackwell, O., Porter, S.A. (1997). An Investigation into the Geotechnical Properties of SoilTyre Mixtures. Environ. Technol. 18, 855-860.

ASTM D 6270 - 98, Standard Practice for Use of Scrap Tires in Civil Engineering Applications.

ATMA (2015). Traction, A newsletter of Automotive Tyre Manufacturers Association, 5(4),1-16. Available online in: http://www.atmaindia.org/pdf/traction-newsletter-aug-2015.pdf

Beena, A., Binod, T., Janak, K. (2016). Geotechnical Properties of Clays Modified with Recycled Crumb Rubber, in: Geotechnical and Structural Engineering Congress 2016. pp. 1404-1413.

Benazzouk, A., Douzane, O., Langlet, T., Mezreb, K., Roucoult, J. M., \& Quéneudec, M. (2007). Physicomechanical properties and water absorption of cement composite containing shredded rubber wastes. Cement and Concrete Composites, 29(10), 732-740.

Bhattacharja, S., Bhatty, J. (2003). Comparative Performance of Portland Cement and Lime in Stabilization of Moderate to High Plasticity Clay Soils. Portl. Cem. Assoc.

Cabalar, A. F. and Karabash, Z. (2015). California Bearing Ratio of a Sub-Base Material Modified With Tire Buffings and Cement Addition, Journal of Testing and Evaluation, 43(6), 1-9.

Cabalar, A.F., Karabash, Z., Mustafa, W.S. (2014). Stabilising a clay using tyre buffings and lime. Road Mater. Pavement Des. 15, 872-891.

Cokca, E., Yilmaz, Z. (2004). Use of rubber and bentonite added fly ash as a liner material. Waste Manag. 24, 153-164.

Guleria, S.P., Dutta, R.K. (2011). Unconfined Compressive Strength of Fly Ash - Lime - Gypsum Composite Mixed with Treated Tire Chips. J. Mater. Civ. Eng. 23, 1255-1263.

Guleria, S.P., Dutta, R.K. (2012). Effect of addition of tire chips on the unconfined compressive strength of fly ash-lime-gypsum mixture. Int. J. Geotech. Eng. 6, 1-13.

Guleria, S.P., Dutta, R.K. (2013). Durability and leachate analysis of fly ash-lime-gypsum composite mixed with treated tire chips. Journal of GeoEngineering, 8(2), 33-40.

Hambirao, G.S., Rakaraddi, P.G. (2014). Soil Stabilization Using Waste Shredded Rubber Tyre Chips. IOSR J. Mech. Civ. Eng. 11, 20-27.

Ho, M., Chan, C. (2010). The Potential of Using Rubberchips as a Soft Clay Stabilizer Enhancing Agent. Mod. Appl. Sci. 4, 122-131. 
IRC:SP:89 (2010). Guidelines for Soil and Granular Material Stabilization using cement lime \&fly ash, published by Indian Roads Congress, New Delhi.

IS : 1498( 1970).Classification and Identification of Soils for General Engineering Purposes, Bureau of Indian Standards, New Delhi (ReaffIrmed 2007).

IS : 2720 (1980). Methods of Test for Soils, Determination of Water Content-Dry Density Relation using Heavy Compaction, Part VIII, Bureau of Indian Standards, New Delhi (Reaffirmed 2011).

IS : 2720 (1991). Methods of Test for Soils, determination of unconfined compression test, Part X, Bureau of Indian Standards, New Delhi (Reaffirmed 2006).

IS : 4332 (1968). Methods of test for stabilized soils,Part IV wetting and drying and freezing and thawing tests for compacted soil-cement mixtures.

Kim, Y.T., Kang, H.S. (2013). Effects of Rubber and Bottom Ash Inclusion on Geotechnical Characteristics of Composite Geomaterial. Mar. Georesources Geotechnol. 31, 71-85.

Otoko, G.R., Pedro, P.P. (2014). Cement Stabilization of Laterite and Chikoko Soils Using Waste Rubber Fibre. Int. J. Eng. Sci. Res. Technol. 3, 130-136.

Prasad, A.S., Ravichandran, P.T., Annadurai, R., Rajkumar, P.R.K. (2014). Study on Effect of Crumb Rubber on Behavior of Soil. Int. J. Geomatics Geosci. 4, 579-584.

Robani, A.R., Chan, B.C.M. (2008). Unconfined compressive strength of clay stabilized with cement-rubber chips. In: Seminar on Unconfined compressive strength of clay stabilized with cement-rubber chips, UTHM.

Shahin, M., Hong, L. (2010). Utilization of Shredded Rubber Tires for Cement-Stabilized Soft Clays, in: Ground Improvement and Geosynthetics - Proceedings of the GeoShanghai International Conference (2010). pp. 181-186.

Srivastava, A., Pandey, S., Rana, J. (2014). Use of shredded tyre waste in improving the geotechnical properties of expansive black cotton soil. Geomech. Geoengin. 9, 303-311.

Tang, C., Shi, B., Gao, W., Chen, F., Cai, Y. (2007). Strength and mechanical behavior of short polypropylene fiber reinforced and cement stabilized clayey soil. Geotext. Geomembranes 25, 194-202.

Wang, F. C., \& Song, W. (2015). Effects of crumb rubber on compressive strength of cement-treated soil. Archives of Civil Engineering, 61(4), 59-78.

Yadav, J.S., Tiwari, S.K. (2016). Behaviour of cement stabilized treated coir fibre-reinforced clay-pond ash mixtures. J. Build. Eng. 8, 131-140.

Yoshio Mitarai, Yoshiaki Kikuchi, Kazuya Yasuhara, Jun Otani, T.N. (2008). The Ductility of Cement Treated Clay with Added Scrape Tire Chips and the change of its Permeability Under Shear Deformation. Japanese Society Civ. Eng. 64, 181-196 (In Japanese). 